\title{
Interpreting temperature information from ice cores along the Antarctic Peninsula: ERA40 analysis
}

\author{
Louise C. Sime, ${ }^{1}$ Gareth J. Marshall, ${ }^{1}$ Robert Mulvaney, ${ }^{1}$ and Elizabeth R. Thomas ${ }^{1}$ \\ Received 1 May 2009; revised 19 June 2009; accepted 27 July 2009; published 16 September 2009.
}

[1] Analysis of ERA40 temperature and accumulation data suggests that annual mean isotopic fluctuations due to temperature change will be geographically very variable across the Peninsula: isotopic variations of $0.4 \%$ at James Ross Island; $0.9 \%$ at Dyer; and $1.3 \%$ at Gomez are all likely to indicate an identical magnitude of temperature change. The reduction in the magnitude of the isotopic signal in the north and east is due to climatically dependent synoptic covariance between temperature and accumulation; whilst in the west and south seasonal covariance amplifies the isotopic temperature signal. Additionally we show that the relationship between accumulation and temperature is rather weak in the north-east regions but is stronger in the central and southerly regions. Therefore isotopes may record $11 \%$ to $30 \%$ of the variance in annual mean temperatures in the north east; $75 \%$ in central regions; and $70 \%$ in the south. This study enables physically based reconstructions of Peninsula climate based on multi-core analysis. Citation: Sime, L. C., G. J. Marshall, R. Mulvaney, and E. R. Thomas (2009), Interpreting temperature information from ice cores along the Antarctic Peninsula: ERA40 analysis, Geophys. Res. Lett., 36, L18801, doi:10.1029/2009GL038982.

\section{Introduction}

[2] The Antarctic Peninsula has been a region of rapid recent climate change [Vaughan et al., 2003]. However, there is a paucity of long term meteorological observations of temperature across the Antarctica Peninsula. Records of the stable isotope composition of oxygen and hydrogen in ice (for brevity we refer to either isotopic record equivalently hereafter as $\delta$ ), can potentially help to fill this gap [Thompson et al., 1994; Mulvaney et al., 2002; Schneider et al., 2006]. This is because, where air parcels travel in isolation, $\delta$ in precipitation is controlled by temperature differences between the evaporation and condensation sites [Dansgaard, 1964; Jouzel et al., 1997]. Where evaporation site temperature remains approximately constant, which seems likely for centennial length studies in the Antarctic vicinity [Schneider et al., 2006], $\delta$ in precipitation is then dependent on the condensation temperature [Dansgaard, 1964]. The individual air parcel model is a simplification, since more complex changes in the mixing of different air parcels can also affect $\delta$ [e.g., Noone, 2008]. However, using a full isotopically enabled general circulation model to simulate a forced warming event, large-scale geographical variability in $\delta$ changes across Antarctica have been

\footnotetext{
${ }^{1}$ British Antarctic Survey, Cambridge, UK.
}

shown to be mainly dependent on local changes in condensation temperature [Sime et al., 2008].

[3] We use ECMWF ERA40 [Uppala et al., 2005] data to examine how local Peninsula changes in the relationship between temperature during precipitation events (condensation temperature) and mean temperature are dependent on modifications of mean Southern Hemisphere atmospheric flow [e.g., Comiso, 2000; Marshall, 2003], and associated changes in synoptic scale activity [e.g., Lubin et al., 2008]. We show that sensitivity across the Peninsula differs from site to site, and this strongly influences how temperature changes can be recorded in $\delta$ at each Peninsula ice core site.

\section{Data and Methods}

[4] We explore the potential impact of changes in the relationship between temperature during precipitation events (condensation temperature) and mean temperature by examining the covariance between temperature and precipitation on Peninsula ice cores using 22 years (1980-2002) of ECMWF ERA40 surface air temperature $(T)$, precipitation $(P)$, and accumulation ( $P E$ - precipitation minus evaporation) data. The ECMWF ERA40 reanalysis is considered more accurate than NCAR-NCEP output for Antarctica [Marshall, 2003; Bromwich and Fogt, 2004], and reliable for both temperature and precipitation across the majority of Peninsula from 1980 onwards [Miles et al., 2008; Marshall, 2009].

[5] The effect of covariance between temperature and precipitation (and accumulation) on the recorded ice core temperature can be investigated by calculating the temperature during precipitation events:

$$
T_{P}=\frac{\overline{T(d) P(d)}}{\overline{P(d)}},
$$

where $T(d)$ is daily temperature ( $d$ is time in daily increments), and $P(d)$ is daily precipitation. We can split $T$ and $P$ into mean and fluctuating parts, so that $T(d)=\overline{T(d)}+$ $T^{\text {synop }}(d)+T^{\text {seas }}(d)+T^{\text {annual }}(d)$, and $P(d)=\overline{P(d)}+P^{\text {synop }}(d)+$ $P^{\text {seas }}(d)+P^{\text {annual }}(d)$. For the example of temperature, $T^{\text {synop }}(d)$ are the fluctuations in $T$ at periods of higher frequency than 60 days (synoptic); $T^{\text {seas }}(d)$ are fluctuations of between 60 and 375 day period (seasonal); and $T^{\text {annual }}(d)$ is remanent low pass variability at periods longer than 375 days. We can expand equation 1 to obtain:

$$
T_{P}=\bar{T}+B_{P}^{\text {synop }}+B_{P}^{\text {seas }}+B_{P}^{\text {annual }},
$$

where the synoptic and seasonal $B$ terms are:

$$
B_{P}^{\text {synop }}=\frac{\overline{T_{\text {synop }}(d) P^{\text {synop }}(d)}}{\overline{P(d)}}, B_{P}^{\text {seas }}=\frac{\overline{T_{\text {seas }}(d) P^{\text {seas }}(d)}}{\overline{P(d)}} .
$$




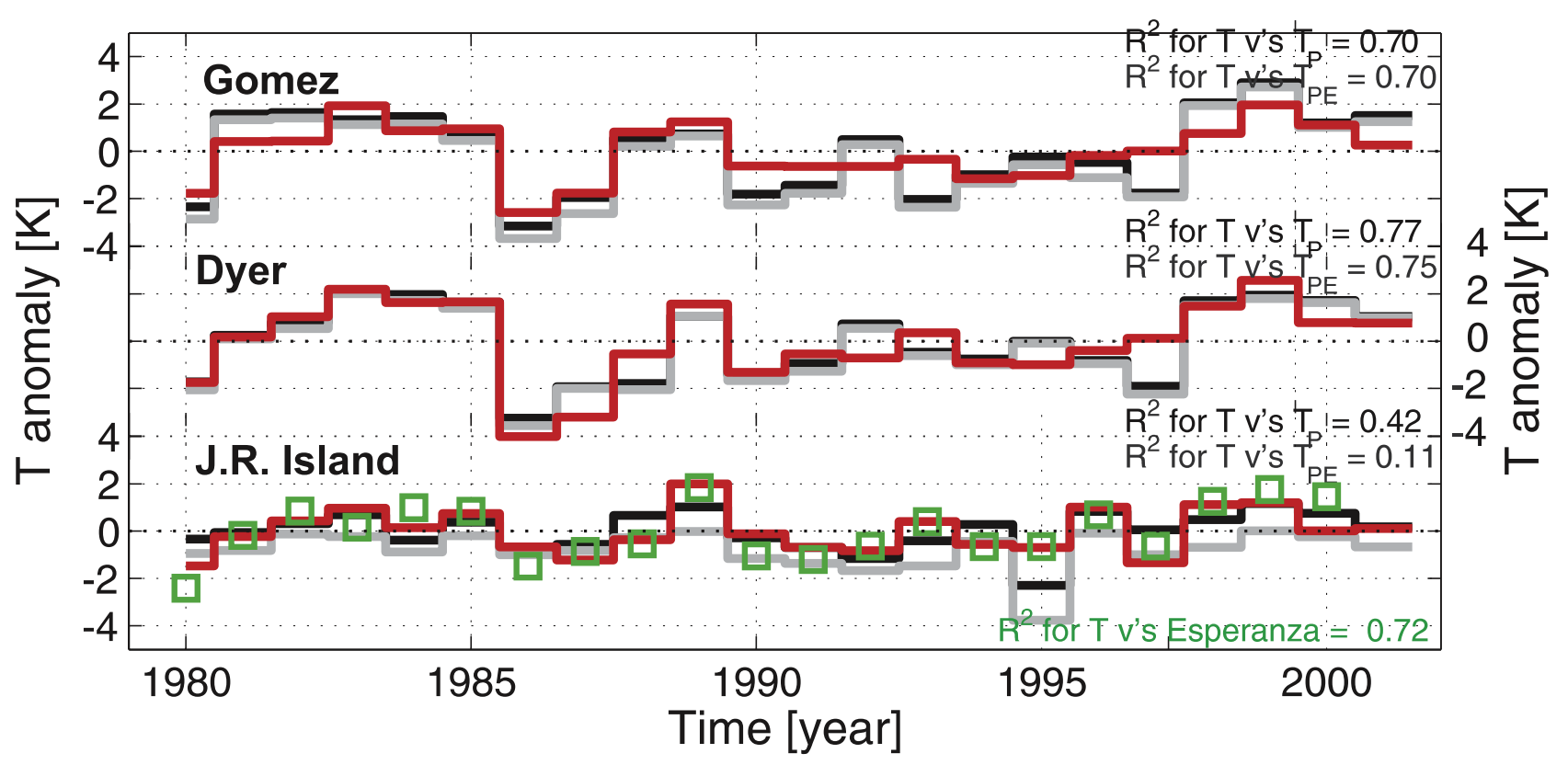

Figure 1. Annual mean temperature (as anomalies) from ERA40 ECMWF reanalysis at three Peninsula ice core sites (see Figure 2a for locations). (top) Gomez, (middle) Dyer, and (bottom) James Ross Island. Solid lines show $T$ (red); $T_{P}$ (black); $T_{P E}$ (grey); and green boxes on Figure 1 (bottom) show annual mean $T$ anomalies from Esperanza Station, which is close to JRI. The explained variance $\left(R^{2}\right)$ between $T$ and $T_{P}$ (and $T$ and $T_{P E}$ ) is given for each site, and $R^{2}$ between the JRI values and the Esperanza observations are also given.

These $B$ terms contain information about biasing in the recorded temperature $T_{P}$, as opposed to the surface temperature $T$, due to correlations between $T$ and $P$ fluctuations at synoptic and seasonal frequencies [Sime et al., 2008]. Note because site location $(x, y)$ appears in every term, it is omitted from all equations.

[6] Peninsula core sites have high accumulation rates and distinct annual cycles in various elements and chemical species [Thomas et al., 2008; Miles et al., 2008]. This allows individual annual layers to be identified in the ice cores, i.e., 'layer counting' [Thompson et al., 1994; Thomas et al., 2008]. Annual layer counting simplifies the reconstruction of annual mean temperatures because annual mean $\delta$ can be obtained for every individual year, regardless of any variations in the annual accumulation amount. However, biasing due to synoptic $\left(B_{P}^{\text {synop }}\right)$ and seasonal $\left(B_{P}^{\text {seas }}\right)$ covariance will affect the annual mean $\delta$. We therefore define annual mean temperature: $T(a)=\overline{T(d)}$, where $a$ is time in annual increments for each Peninsula location and over whole (summer to summer) years between 1980 and 2002. Following that convention, the biasing terms $B_{P}^{\text {seas }}(a)$ and $B_{P}^{\text {synop }}(a)$ are calculated using 365 day sets of frequency filtered $T$ and $P$. Using the definitions in equations 2 and 3 , annual mean precipitation biased temperature is $T_{P}(a)=$ $T(a)+B_{P}^{\text {synop }}(a)+B_{P}^{\text {seas }}(a)$. Likewise temperature biased by only synoptic covariance is $T(a)+B_{P}^{\text {synop }}(a)$, or equivalently for seasonal covariance it is $T(a)+B_{P}^{\text {seas }}(a)$.

[7] Because $\delta$ in ice-core is accumulation, rather than purely precipitation, derived we also carry out the same calculations using accumulation $(P E)$ to obtain $B_{P E}$ and $T_{P E}$ terms. The effect of wind redistribution of snow on accumulation is not included in ERA40 but is thought to be mostly small: $6 \%$ of precipitation across the Peninsula [van Lipzig et al., 2004]. Additionally, $B_{P E}$ and $T_{P E}$ ignore accumulation history, thus any time delays between precipitation and evaporation. However, this omission will have a limited impact on the accuracy of the calculations. Most biasing across the Peninsula is induced by covariance of temperature and precipitation rather than evaporation (see close similarity of black and grey lines in Figure 1).

[8] Neglecting any influence on $\delta$ other than site temperature during precipitation (accumulation), annual mean $T_{P}$ $\left(T_{P E}\right)$ and $\delta$ in ice cores are directly equivalent. Variations in the $T_{P}(a)$ against $T(a)$ relationship can therefore be used to understand how annual mean precipitated $\delta$ relates to annual mean temperature. Similarly, $T_{P E}$ represents the accumulated $\delta$ record. Examining the relationships between $T, T_{P}$, and $T_{P E}$ reveals how past Peninsula temperatures are recorded in the ice core $\delta$ records. We focus here on three Peninsula ice core locations (see Figure 2a for locations): the Gomez, Dyer, and James Ross Island (JRI) regions, which together span the length of the Peninsula.

\section{Results}

[9] Temperature anomalies vary in magnitude across the Peninsula; but warm (and cold) years tend to coincide at all three sites (Figure 1). The Gomez and Dyer regions both show strong annual mean temperature variation (up to $6^{\circ} \mathrm{C}$ variation in $T$ occurs at Dyer), while the JRI region shows more subdued $T$ variations (less than $3^{\circ} \mathrm{C}$ ). Despite the geographic coherence in warm (and cold) years, temperature recorded in precipitation shows large variation between the sites: $T_{P}$ explains at least $70 \%$ of the variance in $T$ at Gomez and Dyer, but only $42 \%$ at JRI, and the accumulation record explains $11 \%$ to $30 \%$ of the mean annual temperature variation in the region of JRI (Figure 2c). This indicates substantial geographical differences in how annual 

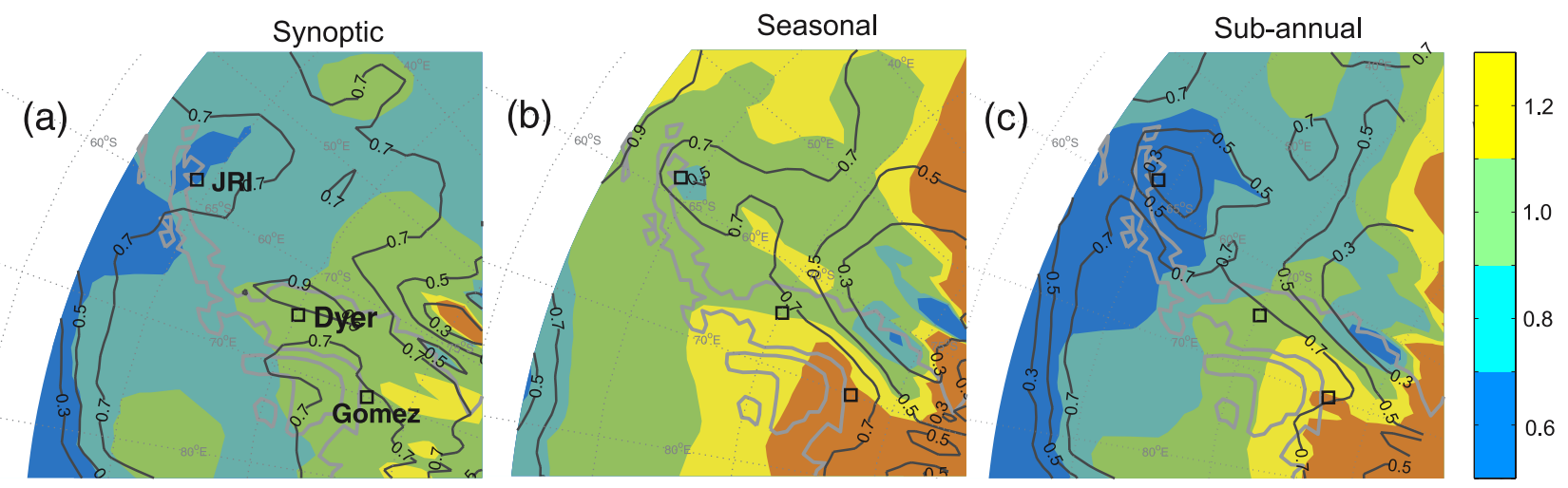

Figure 2. Gradients (shaded) and explained variances $\left(R^{2}\right.$ - contoured in black) between annual mean $T$ and (a) synoptic accumulation biased temperature $\left(T+B_{P E}^{\text {synop }}\right)$, (b) seasonal accumulation biased temperature $\left(T+B_{P E}^{\text {seas }}\right)$, and (c) total subannual accumulation biased temperature $\left(T+B_{P E}^{\text {synop }}+B_{P E}^{\text {seas }}\right) . R^{2}$ intervals are 0.2 , and are shown between 0.3 and 0.9 .

temperatures may be recorded in precipitation and accumulation, and hence annual mean $\delta$ in ice cores.

[10] The relationship between annual mean $T$ and $T_{P E}$ (correlations and gradients) for each location in the Peninsula region depicts the geographical structure in the temperature versus $\delta$ relationship (Figure 2). In the northern and eastern (JRI type) regions, synoptic covariance reduces the correlation and gradient of $T$ versus $T_{P E}$ (Figure 2a, shading). In the more southerly and westerly (Gomez type) regions seasonal covariance increases the gradients (Figure 2b, shading). This split is indicative of different accumulation regimes across the Peninsula. Synoptic precipitation events tend to be associated with positive temperature anomalies [Lubin et al., 2008]. This implies that in warmer (colder) years, warm temperature fluctuations in the JRI region are associated with drier (wetter) conditions, or equally that warm (cold) years have more (less) dry synoptic incursions of warm air. In the more southerly and westerly (Gomez type) regions seasonal covariance increases the gradients (Figure $2 b$, shading), implying that in warm (cold) years warm seasons in this region are associated with wetter (drier) conditions. Further analysis (not shown) confirms that high accumulation years at Gomez tend to be 1 to $2^{\circ} \mathrm{C}$ warmer across the Peninsula including JRI, but high accumulation years at JRI tend to be 1 to $2^{\circ} \mathrm{C}$ cooler across the Peninsula: the correlation between annual mean $T$ and $P$ at Gomez is 0.71 whilst at and JRI it is -0.11 . These type of geographic variations in $P$ (and $P E$ ) and $T$ covariance are associated with changes in atmospheric circulation patterns round Antarctica and are also liable to explain geographical anticorrelation in annual accumulation [e.g., Comiso, 2000; Thomas et al., 2008].

[11] Examination of the spatial correlation of accumulation (or precipitation) events at the two most distant Gomez and JRI regions, and the relationship between the events and temperature and pressure anomalies, clarifies how circulation changes modify the ice core $\delta$ record at each site.

[12] Gomez synoptic accumulation events are associated with strong warming across the Peninsula, particularly in the region between Dyer and Gomez, and with a weaker warming over the JRI region (Figure $3 \mathrm{a}$, shading). The storm track moves southwards and intensifies during these events (Figure 3a, blue and red pressure anomaly contours). The increased meridional pressure gradients cause warmer wetter air to be drawn from the north and west [Thomas et al., 2008]. This warms the Peninsula, and causes higher precipitation over the western and southern Peninsula (Figure 3a, black contours). However, there is no precipitation associated with these events, despite warmer temperatures, across the east and north of the Peninsula. Instead, there is some active drying associated with these conditions across the east and north (Figure $3 b$, grey dashed contours). Thus warming in the east and north due to this circulation pattern is not likely to be recorded in local ice core $\delta$ values. This weakens the relationship between $\delta$ in accumulation and temperature in the JRI region.

[13] Synoptic accumulation events which contribute to the JRI record tend to be more geographically restricted than those at Gomez, and are associated with a smaller amount of warming across the Peninsula (Figure 3d, black contours and shading). They occur when pressure gradients are reduced across northern areas (Figure $3 \mathrm{~d}$, red and blue contours) and warmer wetter air flows from the north east, indicated by a warmed region to the north east of JRI. The synoptic events are associated with a cooling to the south and west of the Peninsula. The seasonal period events are also associated with drying over the south west of the Peninsula (Figure 3e, grey dashed contours).

[14] In summary, Figure 3 indicates that accumulation events at Gomez and JRI occur during different, and to some extent opposite, patterns of atmospheric circulation. This leads to geographically different $\delta$ responses to atmospheric circulation changes, even where the mean annual temperatures response across the Peninsula may be relatively uniform.

[15] The robust structure of results shown here suggests that the geographical gradients in our predicted annual mean $\delta$ against temperature relationship are regionally accurate. However, whilst observations in the north east Peninsula indicate that the ERA40 temperature data is locally reliable (Figure 1, green boxes), accumulation in ERA40 does not reflect the JRI site observations as accurately as it does in the Dyer and Gomez regions [Miles et al., 2008]. The reanalysis JRI elevation is too low [Miles et al., 2008]; although specified sub-grid topographic variance modifies the represented ERA40 Peninsula height [Orr et al., 2008]. The inaccuracy in elevation is liable to contribute to a less realistic ERA40 JRI accumulation regime, although 

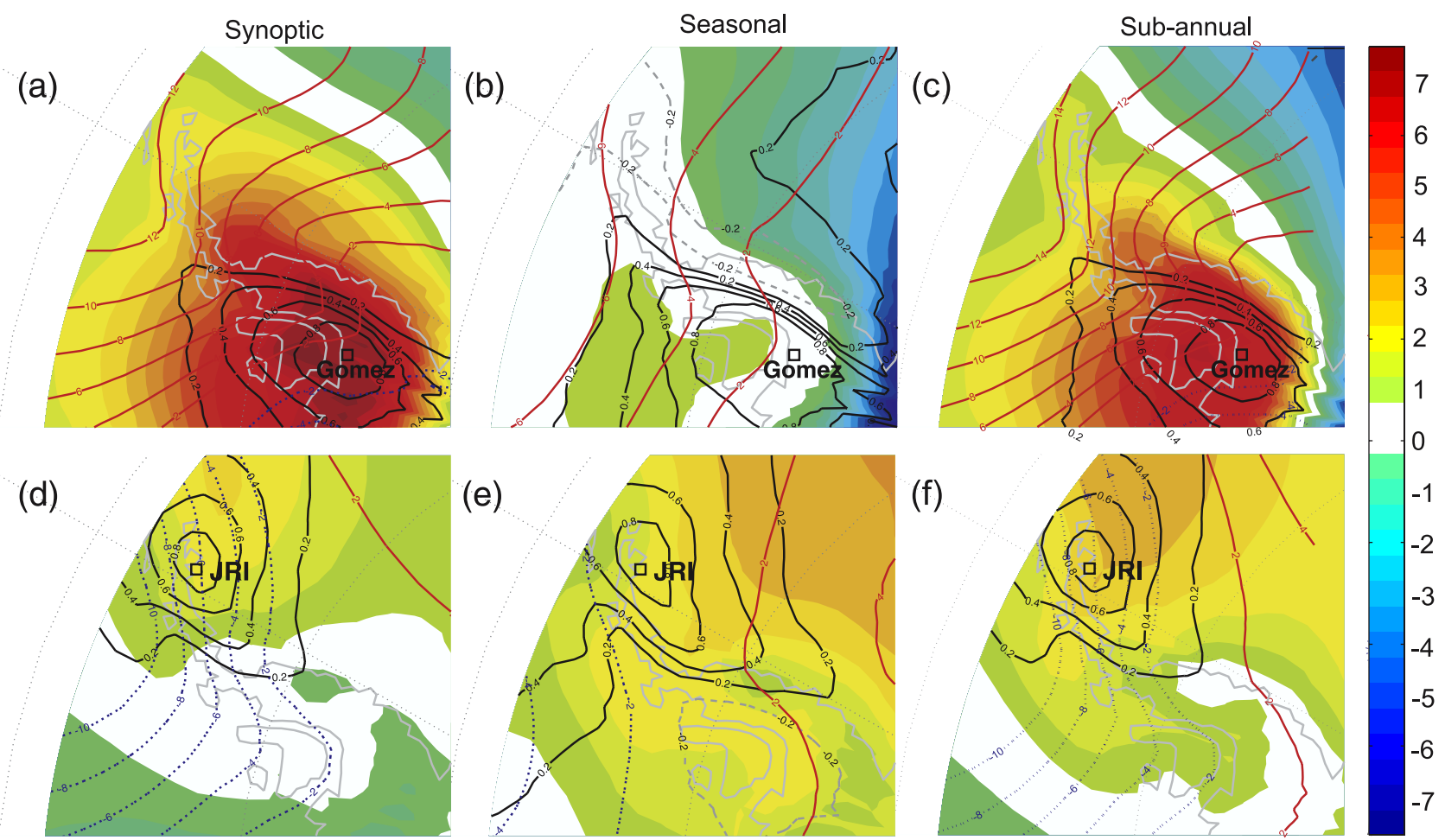

Figure 3. Climatic patterns associated with snow accumulation events at the Gomez and JRI sites. In each case the temperature and pressure maps are formed by averaging the conditions occurring during the top $5 \%$ of $P E$ values in each frequency band. The colour shading is the anomalous temperature pattern associated with accumulation events at the site; the red (positive) and blue (negative) contours are the anomalous pressure patterns associated with accumulation. The black (grey) contours show the region of positive (negative) accumulation during events at each site (i.e., the correlation between $\mathrm{PE}$ at any given location and the accumulation at the reference site (Gomez or JRI)). The patterns shown are those associated with accumulation in the (a and d) synoptic, (b and e) seasonal, and (c and f) all sub-annual frequencies. Intervals are 0.2 for $R$ and 2 for pressure.

we also note that the lack of agreement may also relate to difficulties in observing annual accumulation at JRI. Wind reworking of snow and summer melt layers make JRI a difficult site [Aristarain et al., 1986]. It is likely that the JRI results we present here could be improved by using higher resolution reanalysis, operational forecasts, or regional model output [van Lipzig et al., 2008; Orr et al., 2008]. In the meantime, until higher resolution results are analysed, some caution is required where applying these results to the JRI core observations.

[16] Over longer time periods, other type of change in climate may influence the relationship between annual mean $\delta$ and temperature [e.g., Sime et al., 2008]. Analysis of model runs over centennial timescales will therefore prove necessary for the interpretation of longer Peninsula ice core $\delta$ records.

\section{Conclusions}

[17] The analysis presented here provides powerful insights into the recovery of annual mean temperature information from annual mean ice core $\delta$ records along the Peninsula. We have shown that there are strong geographical gradients in the $\delta$ recording potential across the region, with a particularly poor relationship between $T$ and $\delta$ in the north (and east); here the JRI $\delta$ record could explain only $11 \%$ to $30 \%$ of annual mean temperature variability
(Figures 1 and 2). This is the result of a very weak relationship between sub-annual accumulation and temperature, and implies that understanding annual mean $\delta$ variations will be difficult in this region. The sites of Dyer and Gomez represent easier prospects for obtaining proxy temperature observations. Although we note that the length of $\delta$ record available from these sites is considerably shorter. Dyer $\delta$ may explain $75 \%$ of the local $T$ variations, and the amplitude of $\delta$ variations is approximately 0.9 times the amplitude of the $T$ variations. For the Gomez region, $\delta$ may explain $70 \%$ of the local $T$ variations. However a strong positive $P E$ correlation with $T$, related to variable autumn fluctuations in the SAM [Miles et al., 2008], results in larger amplitude of $\delta$ variations than the $T$ variations. This causes the Gomez $\delta$ record to show stronger fluctuations than $T$, thus $\delta$ in this region may show 1.3 times the expected fluctuation for a given change in $T$. This north to south trend in the $T$ against $\delta$ relationship is caused by differing accumulation against temperature responses under conditions of intensified westerly flow.

[18] These findings imply that caution should be attached to the interpretation of the magnitude of $\delta$ fluctuations for individual Peninsula ice cores: a $0.4 \%$ JRI; $0.9 \%$ Dyer; and $1.3 \%$ o Gomez change in $\delta$ could all indicate an identical magnitude temperature change. Additionally, because the northern Peninsula exhibits smaller annual mean temperature fluctuations than the southern Peninsula, annual mean 
isotopic fluctuations around JRI due to annual temperature changes could be quite small. However, the differences we have found here show that by utilising multiple Peninsula ice cores $\delta$ records, particularly alongside annual mean accumulation values, a detailed reconstruction of the past Peninsula climate is possible. This because the core sites respond differently to circulation changes; particularly the intensity of westerly flows. Thus multi-core reconstructions in this region could provide powerful proxy evidence of past Peninsula climate.

[19] Acknowledgments. Thanks to Eric Wolff for comments and helpful discussion.

\section{References}

Aristarain, A., J. Jouzel, and M. Purchet (1986), Past Antarctic Peninsula climate (1985-1980) deduced from an ice core isotope records, Clim. Change, 8, 69-89.

Bromwich, D. H., and R. L. Fogt (2004), Strong trends in the skill of the ERA-40 and NCEP-NCAR reanalyses in the high and midlatitudes of the Southern Hemisphere, 1958-2001, J. Clim., 17, 4603-4619.

Comiso, J. C. (2000), Variability and trends in Antarctic surface temperatures from in situ and satellite infrared measurement, J. Clim., 13 , $1674-1696$.

Dansgaard, W. (1964), Stable isotopes in precipitation, Tellus, 16, 436-468.

Jouzel, J., et al. (1997), Validity of the temperature reconstruction from water isotopes in ice cores, J. Geophys. Res., 102(C12), 26,471-26,487.

Lubin, D., R. A. Wittenmyer, D. H. Bromwich, and G. J. Marshall (2008), Antarctic Peninsula mesoscale cyclone variability and climatic impacts influenced by the SAM, Geophys. Res. Lett., 35, L02808, doi:10.1029/ 2007GL032170.

Marshall, G. J. (2003), Trends in the southern annular mode from observations and reanalyses, J. Clim., 16, 4134-4143.

Marshall, G. J. (2009), On the annual and semi-annual cycles of precipitation across Antarctica, Int. J. Climatol, doi:10.1002/joc.1810, in press.

Miles, G. M., G. J. Marshall, J. R. Mcconnell, and A. J. Aristarain (2008), Recent accumulation variability and change on the Antarctic Peninsula from the ERA40 reanalysis, Int. J. Climatol., 28, 1409-1422.

Mulvaney, R., H. Oerter, D. A. Peel, W. Graf, C. Arrowsmith, E. C. Pasteur, B. Knight, G. C. Littot, and W. D. Miners (2002), 1000 year ice-core records from Berkner Island, Antarctica, Ann. Glaciol., 35, 45-51.
Noone, D. (2008), The influence of midlatitude and tropical overturning circulation on the isotopic composition of atmospheric water vapor and Antarctic precipitation, J. Geophys. Res., 113, D04102, doi:10.1029/ 2007JD008892.

Orr, A., G. J. Marshall, J. C. Hunt, J. Sommeria, C.-G. Wang, N. P. van Lipzig, D. Cresswell, and J. C. King (2008), Characteristics of summer airflow over the Antarctic Peninsula in response to recent strengthening of westerly circumpolar winds, J. Atmos. Sci., 65, 1396-1413.

Schneider, D. P., E. J. Steig, T. D. van Ommen, D. A. Dixon, P. A. Mayewski, J. M. Jones, and C. M. Bitz (2006), Antarctic temperatures over the past two centuries from ice cores, Geophys. Res. Lett., 33 L16707, doi:10.1029/2006GL027057.

Sime, L. C., J. C. Tindall, E. W. Wolff, W. M. Connolley, and P. J. Valdes (2008), Antarctic isotopic thermometer during a $\mathrm{CO}_{2}$ forced warming event, J. Geophys. Res., 113, D24119, doi:10.1029/2008JD010395.

Thomas, E. R., G. J. Marshall, and J. R. McConnell (2008), A doubling in snow accumulation in the western Antarctic Peninsula since 1850, Geophys. Res. Lett., 35, L01706, doi:10.1029/2007GL032529.

Thompson, L. G., D. A. Peel, E. Mosley-Thompson, R. Mulvaney, J. Dai, P. N. Lin, M. E. Davis, and C. F. Raymond (1994), Climate since AD 1510 on Dyer Plateau, Antarctic Peninsula: Evidence for recent climate change, Ann. Glaciol., 20, 420-426.

Uppala, S. M., et al. (2005), The ERA-40 re-analysis, Q. J. R. Meteorol. Soc., 131, 2961-3012.

van Lipzig, N. P. M., J. C. King, T. A. Lachlan-Cope, and M. R. van den Broeke (2004), Precipitation, sublimation, and snow drift in the Antarctic Peninsula region from a regional atmospheric model, J. Geophys. Res., 109, D24106, doi:10.1029/2004JD004701.

van Lipzig, N. P., G. J. Marshall, A. Orr, and J. C. King (2008), The relationship between the Southern Hemisphere Annular Mode and Antarctic Peninsula summer temperatures: Analysis of a high-resolution model climatology, J. Clim., 21, 1649-1668.

Vaughan, D., G. Marshall, W. Connolley, C. Parkinson, R. Mulvaney, D. Hodgson, J. King, C. Pudsey, and J. Turner (2003), Recent rapid regional climate warming on the Antarctic Peninsula, Clim. Change, $60,243-274$

G. J. Marshall, R. Mulvaney, L. C. Sime, and E. R. Thomas, British Antarctic Survey, High Cross, Madingley Road, Cambridge CB3 0ET, UK. (1sim@bas.ac.uk) 